\title{
Figure S7A
}
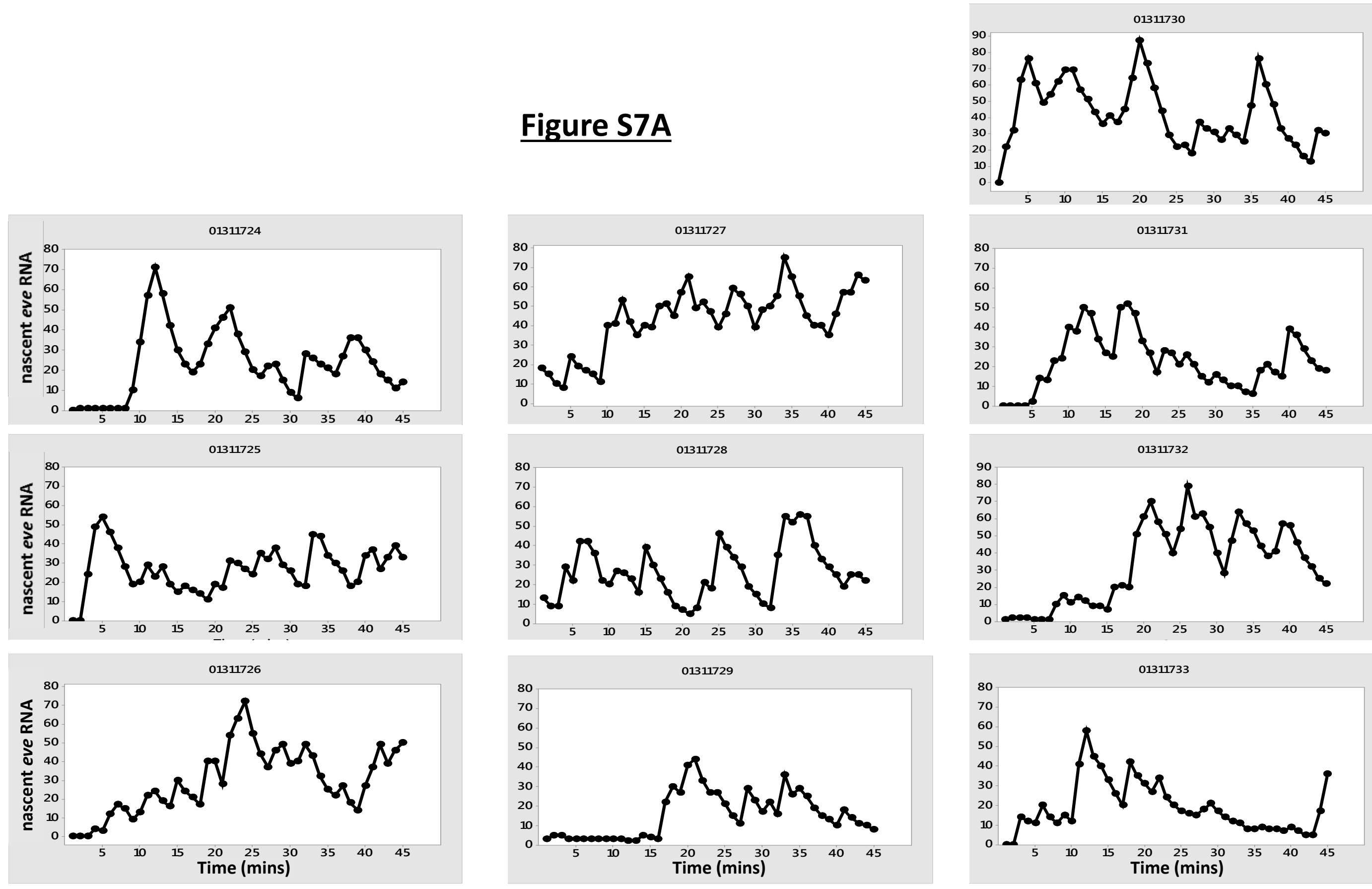


\section{Figure S7B}
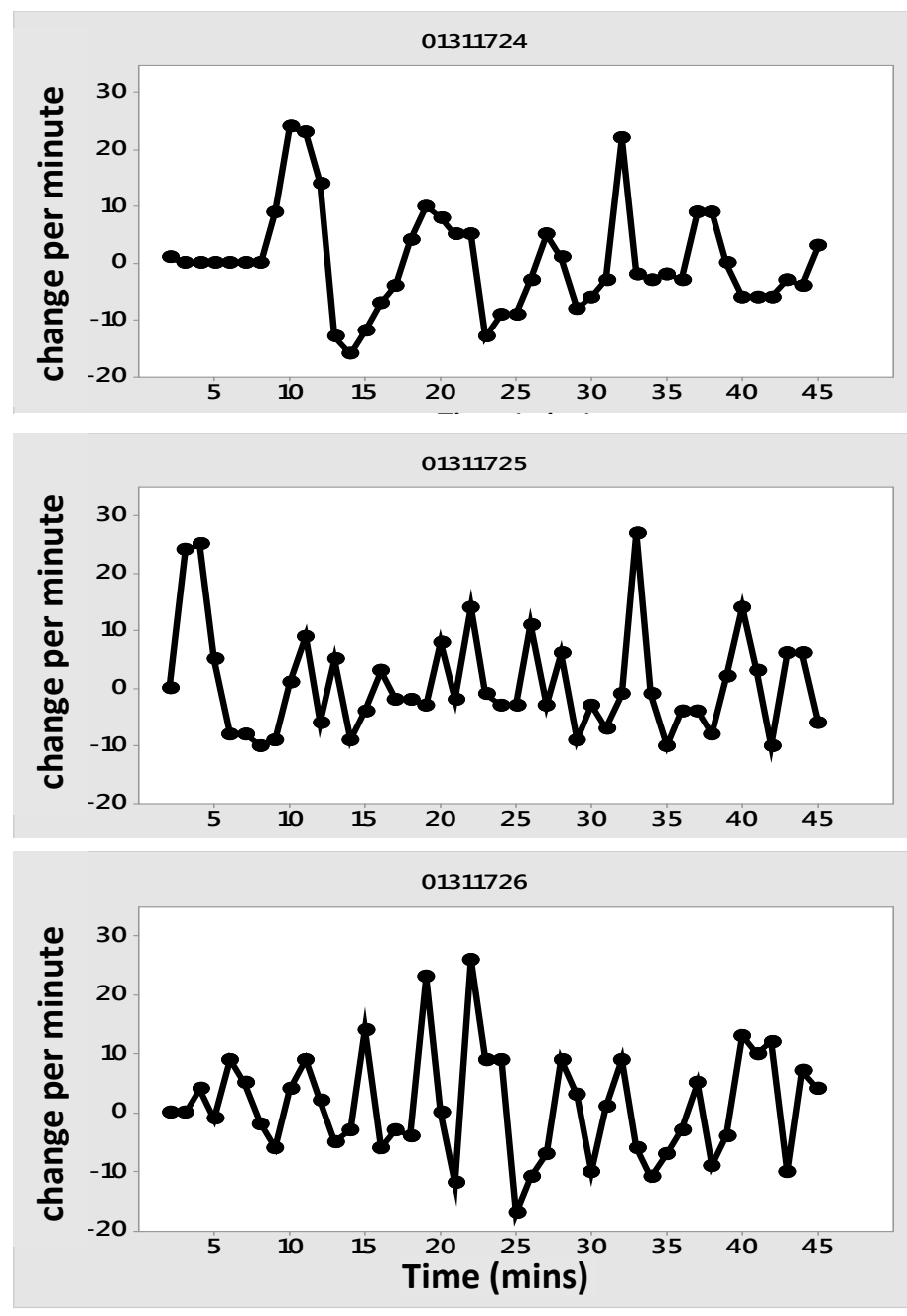

01311727
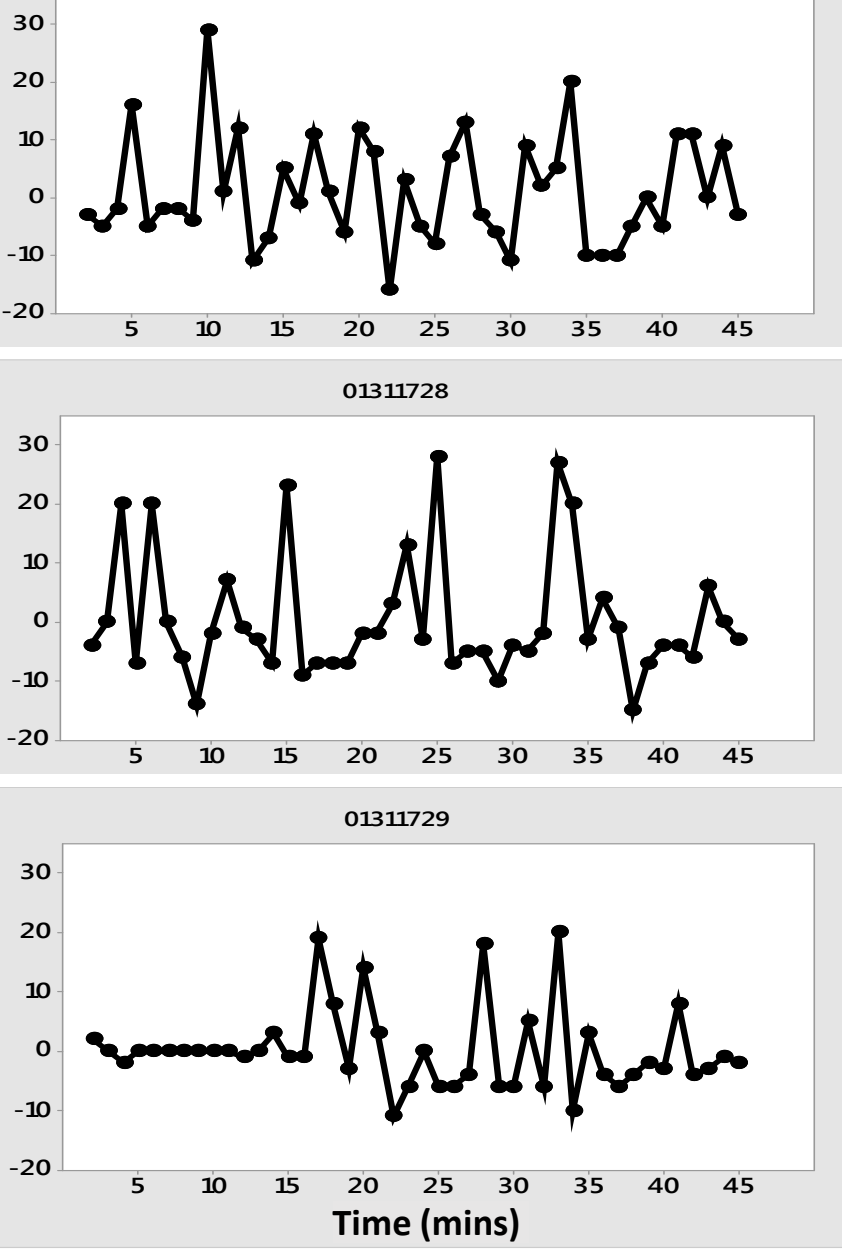
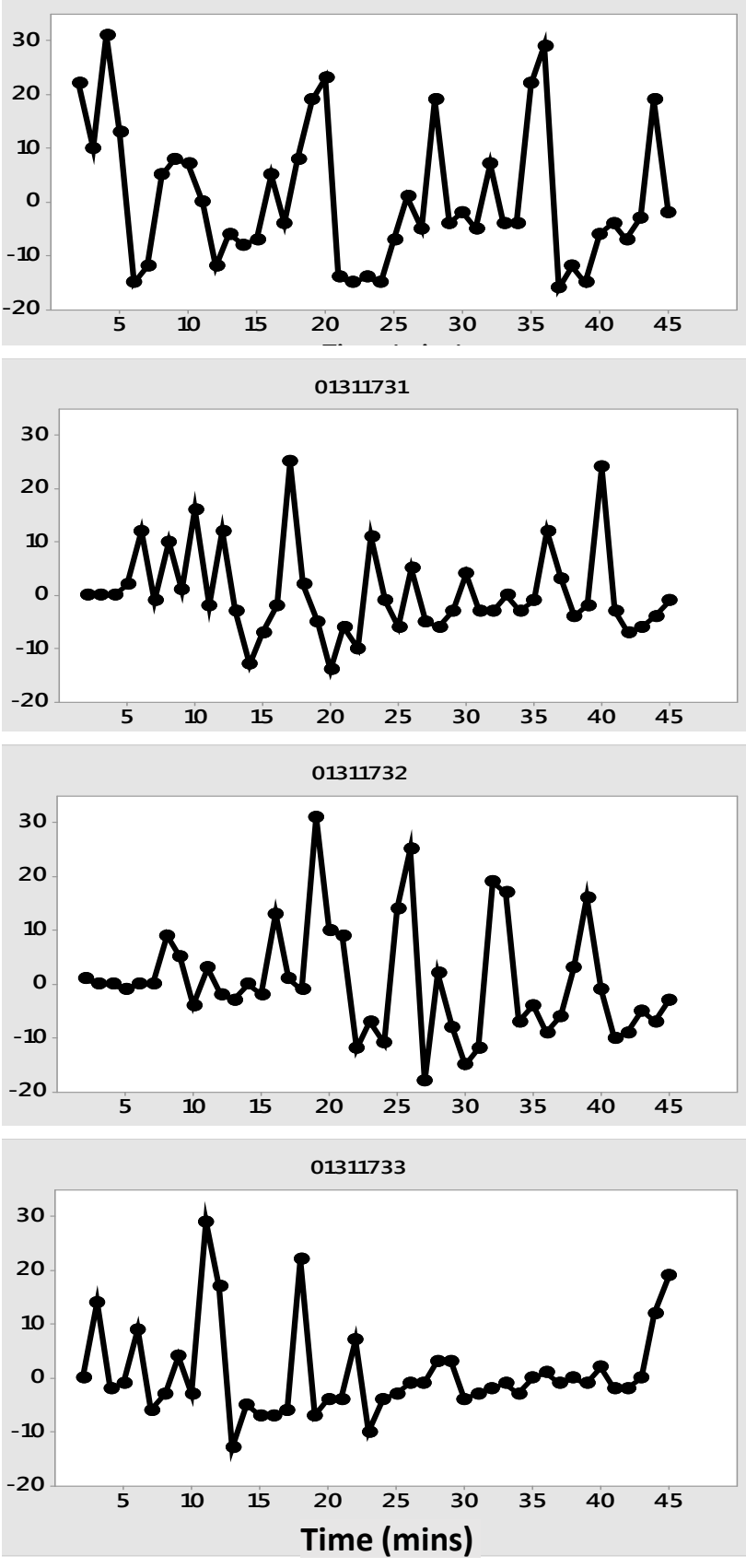


\section{Figure S7C}
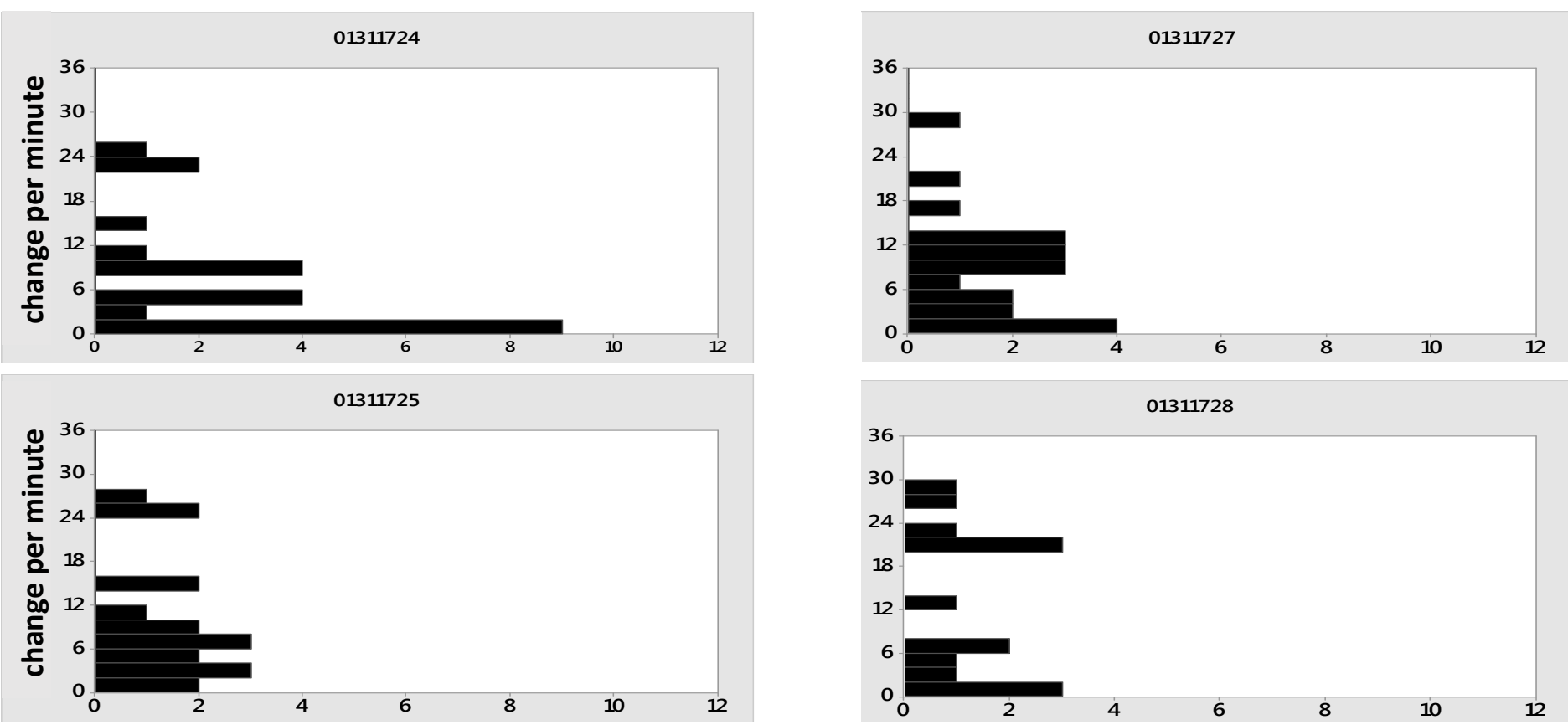

01311725
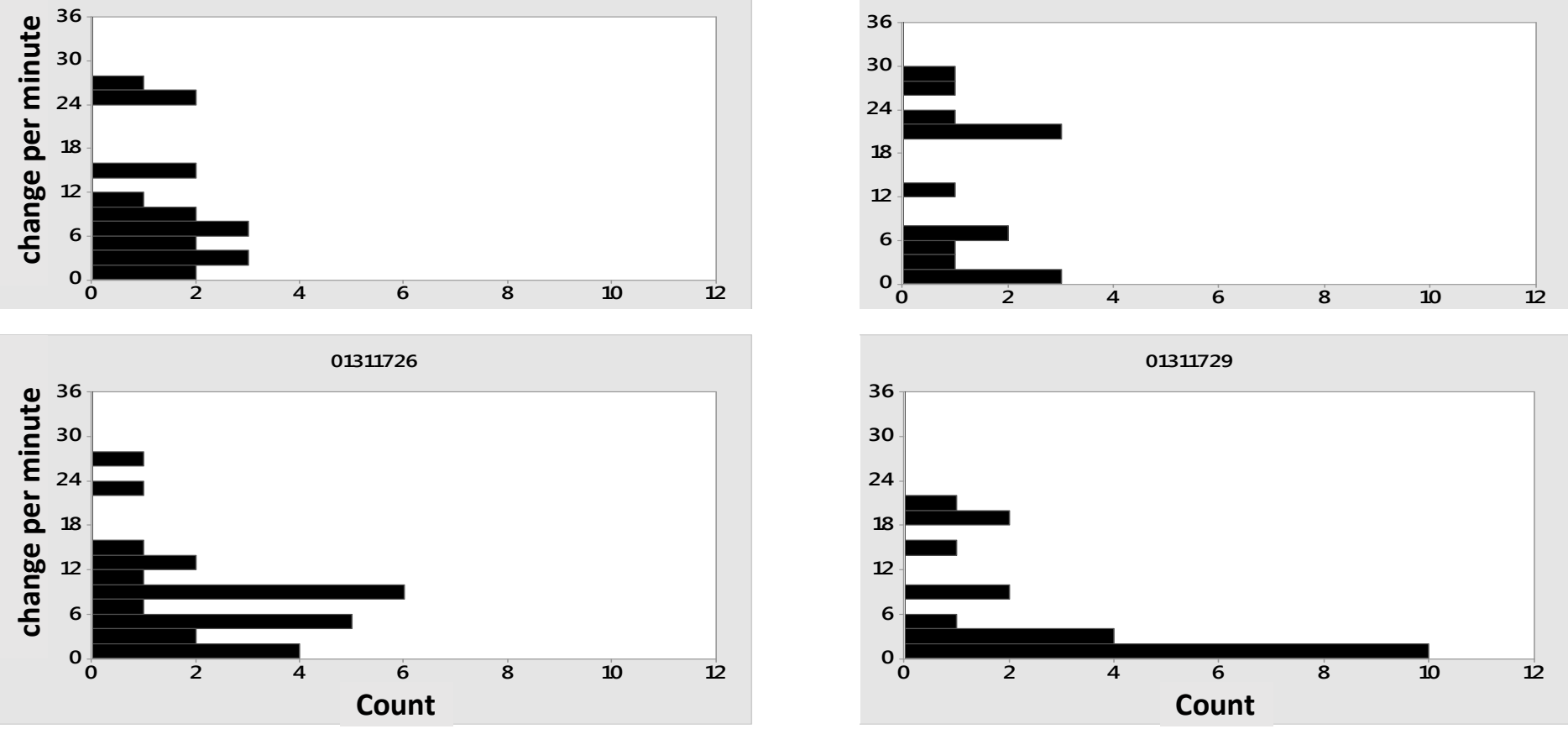
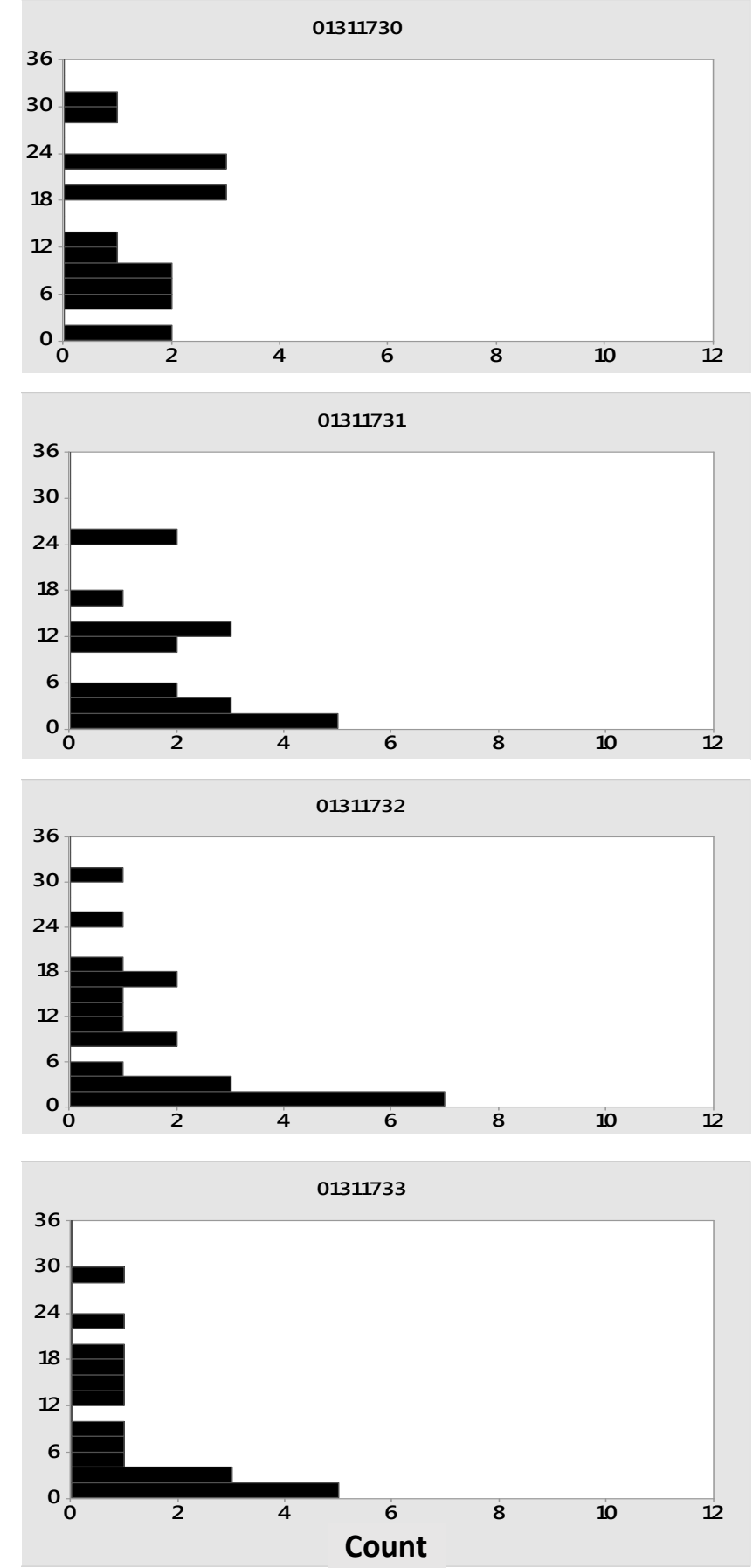